\title{
CHEK2 c.1100delC mutation is associated with an increased risk for male breast cancer in Finnish patient population
}

\author{
Sanna Hallamies ${ }^{1}$, Liisa M. Pelttari ${ }^{2}$, Paula Poikonen-Saksela' ${ }^{1}$, Antti Jekunen ${ }^{3}$, Arja Jukkola-Vuorinen ${ }^{4}$, Päivi Auvinen ${ }^{5}$,
} Carl Blomqvist ${ }^{1}, K^{2}$ ristiina Aittomäki ${ }^{6}$, Johanna Mattson ${ }^{1 \dagger}$ and Heli Nevanlinna ${ }^{2^{*+}}$ (D)

\begin{abstract}
Background: Several susceptibility genes have been established for female breast cancer, of which mutations in BRCA1 and especially in BRCA2 are also known risk factors for male breast cancer (MBC). The role of other breast cancer genes in MBC is less well understood.

Methods: In this study, we have genotyped 68 MBC patients for the known breast or ovarian cancer associated mutations in the Finnish population in CHEK2, PALB2, RAD51C, RAD51D, and FANCM genes.

Results: CHEK2 c.1100delC mutation was found in 4 patients (5.9\%), which is significantly more frequent than in the control population (OR: 4.47, 95\% Cl 1.51-13.18, $p=0.019$ ). Four CHEK2 I157T variants were also detected, but the frequency did not significantly differ from population controls $(p=0.781)$. No RAD51C, RAD51D, PALB2, or FANCM mutations were found.
\end{abstract}

Conclusions: These data suggest that the CHEK2 c.1100delC mutation is associated with an increased risk for MBC in the Finnish population.

Keywords: Male breast cancer, CHEK2 c.1100delC

\section{Background}

Male breast cancer $(\mathrm{MBC})$ is a rare disease comprising less than $1 \%$ of all cancer in men and less than $1 \%$ of all breast cancers, but the incidence is increasing [1]. Associated genetic risk factors for $\mathrm{MBC}$ are poorly understood. Mutations in BRCA1 and especially in $B R C A 2$ are known risk factors, the prevalence varying in different MBC populations [1, 2]. According to a study in 2004, 7.8\% of Finnish MBC patients carried a BRCA2 mutation [3]. In Finland, strong founder effects and enrichment of deleterious alleles are seen [4] and major founder mutations in BRCA1 and BRCA2 [5] as well as in other breast and ovarian cancer susceptibility genes account for the vast majority of the identified mutations.

\footnotetext{
* Correspondence: heli.nevanlinna@hus.fi

${ }^{\dagger}$ Equal contributors

${ }^{2}$ Department of Obstetrics and Gynecology, University of Helsinki and Helsinki University Hospital, Helsinki, Finland

Full list of author information is available at the end of the article
}

Mutations in cell-cycle checkpoint kinase 2 (CHEK2) are associated with an elevated risk for breast cancer $[6,7]$. Approximately 4 -fold elevated frequency of a protein truncating mutation, c.1100delC in exon 10, was found in Finnish breast cancer patients with a positive family history (5.5\%) compared to population controls (1.4\%) and a 6-fold in patients with bilateral breast cancer compared to patients with unilateral disease [8]. Among unselected female breast cancer patients, the mutation was observed at a $2.0 \%$ frequency. In a previous study of Finnish MBC patients, the frequency of the c.1100delC mutation was similar to that seen in population controls [9] while in a Dutch and an American study, the frequency was significantly elevated $[10,11]$. Another variant, the missense I157T (c.470T>C) in the FHA domain of CHEK2, is associated with a milder elevation in the risk and was observed in $7.4 \%$ of unselected female breast cancer patients, in $5.5 \%$ of familial patients, and in $5.3 \%$ of population controls [12]. In a recent study [13], the incidence of germline mutations in genes mediating DNA-repair processes among men with metastatic 
prostate cancer was $11.8 \%$, which was significantly higher than the incidence among men with localized cancer. The results indicated that a CHEK2 $(p<0.001)$ or a BRCA2 $(p<0.001)$ mutation may be associated with an elevated risk for a more aggressive type of prostate cancer.

Fanconi anemia is a genetically heterogeneous recessive disorder, which results from biallelic mutations in FA genes, a family of more than 20 genes involved in DNA repair [14]. An increased risk of breast or ovarian cancer is associated with monoallelic mutations in a subset of these genes (BRCA1, BRCA2, BRIP1, PALB2, RAD51C) [15-20]. In the Finnish population, founder mutations in BRCA2, PALB2, and $R A D 51 C$ genes have been identified [5, 18, 21]. PALB2 c.1592delT mutation has been observed at $0.7-0.9 \%$ frequency among Finnish unselected breast cancer patients and at $2.0-2.7 \%$ frequency among familial patients and is associated with an aggressive breast tumour phenotype [21, 22]. $R A D 51 C$ mutations c.93delG and c. $837+1 G>A$ were observed at a combined frequency of $1.0 \%$ among unselected ovarian cancer patients and at $2.1 \%$ frequency among breast and ovarian cancer families and associated with an increased risk of ovarian cancer [18]. Neither of the mutations was observed in unselected breast cancer patients. Mutations in $R A D 51 D$ are associated with an increased risk of ovarian cancer [23] and a Finnish founder mutation c. $576+1 \mathrm{G}>\mathrm{A}$ in the gene was significantly more frequent among breast cancer patients with a family history of breast and ovarian cancer $(2.9 \%)$ than among population controls (0.1\%) [24]. Among Finnish unselected ovarian cancer patients, the frequency of the c.576+1G>A mutation was $0.6 \%$ whereas the frequency among unselected breast cancer patients $(0.1 \%)$ was same as in controls [24]. Finally, a FANCM nonsense mutation c.5101C>T (p.Q1701X) has been identified as a susceptibility allele for triple-negative breast cancer in the Finnish population and was observed in $2.8 \%$ of unselected breast cancer patients and in $3.1 \%$ of breast cancer families [25].

Here we have genotyped the CHEK2 mutations I157T and c.1100delC, the FANCM mutation p.Q1701X, the PALB2 mutation c.1592delT, the RAD51C mutations c.837+1G $>\mathrm{A}$ and c.93delG, and the $R A D 51 D$ mutation c. $576+1 \mathrm{G}>\mathrm{A}$ in 68 male breast cancer patients. These mutations explain the vast majority of all mutations observed in these genes in the Finnish population, with only a few other, very rare or unique mutations identified.

\section{Methods}

\section{Patients}

We determined the frequency of these mutations in 68 male breast cancer patients. An unselected series of 59 male breast cancer cases was collected at the Helsinki University Hospital Department of Oncology. Altogether 40 patients, diagnosed with breast cancer in 1997-2007 in Helsinki $(n=26)$, Kuopio $(n=2)$, Oulu $(n=6)$ and Vaasa $(n=6)$, were retrospectively collected in 2009-2012. The series included $32 \%$ of all male breast cancer cases diagnosed between 1997 and 2007 and 65\% of those patients who were alive during the collection period. In addition, 19 patients diagnosed between 2008 and 2013 in Helsinki were collected in 2011-2014 (including 90\% of all male breast cancer cases diagnosed in 2008-2013 in Helsinki). One male breast cancer case was identified as part of an unselected series of breast cancer patients collected at the Helsinki University Hospital Department of Surgery in 2001-2004 [26] and eight BRCA1/2 negative male breast cancer cases diagnosed between 1999 and 2014 were collected at the Helsinki University Hospital Department of Clinical Genetics in 2002-2014. A written, informed consent and a blood sample were obtained from all subjects.

Clinical data including risk factors, patient and primary tumour characteristics were obtained by chart review. Obesity was estimated by calculating body mass index (BMI, > 30 obese) from height and weight recorded in patient charts.

\section{Genotyping}

We genotyped the RAD51D c.576+1G>A, RAD51C c.93delG, and $R A D 51 C$ c.837+1G $>$ A mutations with Taqman real-time PCR as described elsewhere [18, 24]. The PALB2 c.1592delT, the FANCM c.5101C > T, and the CHEK2 mutations were genotyped with Sanger sequencing using primer pairs described in Additional file 1 for PCR and ABI BigDyeTerminator 3.1 Cycle Sequencing Kit (Life Technologies) for the sequencing reactions. The capillary sequencing was performed at the Institute for Molecular Medicine Finland (FIMM), University of Helsinki.

For the analysis, we used population control frequencies in the Finnish population defined in previous studies in up to 2102 healthy female population controls from Helsinki $(n=1287)$ and Tampere $(n=815)$ area from the Finnish Red Cross Blood Transfusion Service for the CHEK2 [8, 12], RAD51D [24], FANCM [25], and RAD51C mutations [18], and 1079 healthy population controls from the Helsinki region for the PALB2 mutation [22].

The statistical analysis was done using the SPSS 22 for MAC. $P$ values for comparisons of male breast cancer patients and population controls were calculated using Fisher's exact test. All $P$ values are two sided.

\section{Results}

The median age at diagnosis of breast cancer was 64 years (range 24-90).

The occurrence of risk factors in the studied patients is presented in Additional file 2. Forty-one patients had been tested for BRCA mutations, and of these, 2 (4.9\%) were carriers of $B R C A 1$ mutations and $3(7.3 \%)$ carried a BRCA2 mutation.

The tumour characteristics are described in Table 1. Nine percent of patients had a T4 tumour. One patient 
Table 1 Tumour characteristics

\begin{tabular}{|c|c|c|c|}
\hline Tumour characteristics & & No. (of 68) & Proportion \\
\hline \multirow[t]{5}{*}{ T-status } & $\mathrm{T} 1$ & 36 & $53 \%$ \\
\hline & $\mathrm{T} 2$ & 20 & $29 \%$ \\
\hline & T3 & 0 & $0 \%$ \\
\hline & T4 & 6 & $9 \%$ \\
\hline & Unknown & 6 & $9 \%$ \\
\hline \multirow[t]{3}{*}{ Lymph node status } & Positive & 22 & $32 \%$ \\
\hline & Negative & 34 & $50 \%$ \\
\hline & Unknown & 12 & $18 \%$ \\
\hline \multirow[t]{3}{*}{ Histologic tumour type } & Ductal & 65 & $96 \%$ \\
\hline & Lobular & 1 & $1 \%$ \\
\hline & Other & 2 & $3 \%$ \\
\hline \multirow[t]{3}{*}{ ER status } & Positive & 62 & $91 \%$ \\
\hline & Negative & 2 & $3 \%$ \\
\hline & Unknown & 4 & $6 \%$ \\
\hline \multirow[t]{3}{*}{ PR status } & Positive & 55 & $81 \%$ \\
\hline & Negative & 6 & $9 \%$ \\
\hline & Unknown & 7 & $10 \%$ \\
\hline \multirow[t]{4}{*}{ Grade } & 1 & 6 & $9 \%$ \\
\hline & 2 & 30 & $44 \%$ \\
\hline & 3 & 24 & $35 \%$ \\
\hline & Unknown & 8 & $12 \%$ \\
\hline \multirow[t]{3}{*}{ Her2 } & Positive & 8 & $12 \%$ \\
\hline & Negative & 42 & $62 \%$ \\
\hline & Unknown & 18 & $26 \%$ \\
\hline
\end{tabular}

had a lobular carcinoma, one an adenocystic carcinoma, and one a ductal carcinoma in situ whereas all other cancers were ductal carcinomas. Most tumours were hormone receptor positive: $91 \%$ were estrogen receptor (ER) positive and $81 \%$ progesterone receptor (PR) positive.

The frequencies of mutations detected in this study and in the control populations are presented in Table 2. The CHEK2 c.1100delC mutation was found in 4 patients (5.9\%) (odds ratio (OR): 4.47, 95\% confidence interval (CI)
1.51-13.18, $p=0.021$ compared to population controls). Median age of the CHEK2 c.1100delC carriers was 56 years and half of the patients were relatively young at the time of diagnosis, less than 50 years old (Table 3). All the carriers were $B R C A 1 / 2$ negative and one patient had a family history of breast cancer. All carcinomas were ductal and estrogen receptor positive. The I157T variant was also detected in 4 patients $(p=0.781)$. No RAD51C, FANCM, $P A L B 2$, or $R A D 51 D$ mutations were found.

\section{Discussion}

The CHEK2 c.1100delC mutation associated with an increased risk for $\mathrm{MBC}$ in the Finnish population of the present study. None of the patients with CHEK2 c.1100delC mutation had BRCA1/2 mutation. Mutations in $C H E K 2$ are known risk factors for female breast cancer [7]. The 5.9\% mutation frequency detected among the male breast cancer patients is higher than among the unselected female patients and comparable to that among female familial cases (5.5\%) [8]. Similar to female breast cancer [27], the male CHEK2 c.1100delC carrier tumours were of ductal histology, ER positive, and poorly differentiated (grade 2-3). The CHEK2 c.1100delC mutation has been also linked to an increased risk for prostate cancer [28], and possibly indicates an elevated risk for metastatic prostate cancer [13].

The role of the CHEK2 c.1100delC mutation as a risk factor for $\mathrm{MBC}$ has been studied in several papers [6, 911, 29-32]. An association between CHEK2 c.1100delC mutation and $\mathrm{MBC}$ risk has been reported in three studies $[6,10,11]$. A wide variation in the population frequency of c.1100delC has been observed, with highest reported frequencies in the Netherlands (1.3-1.6\%) and in Finland (1.1-1.4\%) [7]. The rarity of $\mathrm{MBC}$ and the geographic variation in the frequency of the CHEK2 c.1100delC mutation might explain the differences between studies on the possible association between the CHEK2 c.1100delC mutation and MBC. In a previous Finnish study, the CHEK2 c.1100delC mutation frequency was not significantly elevated in $\mathrm{MBC}$ patients,

Table 2 The frequencies of mutations detected in study and control populations

\begin{tabular}{|c|c|c|c|c|c|c|c|c|}
\hline Mutation & This study & Freq $^{a}$ & Controls $^{b}$ & Freq $^{c}$ & $p$-value & OR & $95 \% \mathrm{Cl}$ & Ref \\
\hline CHEK2 c.1100delC & 4 of 68 & 0.059 & 26 of 1885 & 0.014 & 0.019 & 4.47 & $1.51-13.18$ & 8 \\
\hline CHEK2 I157T & 4 of 68 & 0.059 & 100 of 1885 & 0.053 & 0.781 & 1.12 & $0.40-3.13$ & 12 \\
\hline PALB2 c.1592delT & 0 of 68 & 0 & 2 of 1079 & 0.002 & 1 & n.a. & n.a. & 22 \\
\hline FANCM p.Q1701X & 0 of 68 & 0 & 38 of 2080 & 0.018 & 0.632 & n.a. & n.a. & 25 \\
\hline RAD51C c.93delG & 0 of 68 & 0 & 2 of 2086 & 0.001 & 1 & n.a. & n.a. & 18 \\
\hline RAD51C c.837+1G >A & 0 of 68 & 0 & 0 of 2086 & 0 & 1 & n.a. & n.a. & 18 \\
\hline RAD51D c.576+1G>A & 0 of 68 & 0 & 1 of 2102 & 0 & 1 & n.a. & n.a. & 24 \\
\hline
\end{tabular}

${ }^{a}$ mutation frequency in this study

${ }^{b}$ see cited reference for control populations

cmutation frequency in controls 
Table 3 Clinical and pathological characteristics of the CHEK2 c.1100delC carriers

\begin{tabular}{|c|c|c|c|c|c|c|c|c|c|c|c|c|}
\hline $\begin{array}{l}\text { Age range at } \\
\text { diagnosis }\end{array}$ & $\mathrm{T}$ & N & M & Histology & ER & PR & Grade & Her2 & $\begin{array}{l}\text { Family history of } \\
\text { breast cancer }\end{array}$ & $\begin{array}{l}\text { Family history of } \\
\text { prostate cancer }\end{array}$ & $\begin{array}{l}\text { Family history of } \\
\text { ovarian cancer }\end{array}$ & $\begin{array}{l}\text { BRCA1/2 } \\
\text { mutation }\end{array}$ \\
\hline 65-70 & 1 & 1 & 0 & Ductal & Positive & Positive & 3 & n.a. & n.a. & n.a. & n.a. & Negative \\
\hline $45-50$ & 1 & 0 & 0 & Ductal & Positive & Negative & 2 & n.a. & Negative & Negative & Negative & Negative \\
\hline $40-45$ & 1 & 1 & 0 & Ductal & Positive & Negative & 3 & Negative & Positive & n.a. & n.a. & Negative \\
\hline $75-80$ & 1 & 0 & 0 & Ductal & Positive & Positive & 2 & Positive & Negative & n.a. & n.a. & Negative \\
\hline
\end{tabular}

and did not seem to affect the age on breast cancer onset [9]. Only $10.5 \%$ of patients in that study had a family history of female breast or ovarian cancer. In our study, however, the CHEK2 c.1100delC was significantly more frequent in the studied population compared to population controls, despite the smaller sample size. The median age of the patients with CHEK2 c.1100delC mutation was also younger than in the whole population studied. Of the 43 patients with known family history, $25 \%$ had a positive family history of female breast cancer. The population control frequency to which the previous study compared their results was the same as the one used in this study. Our finding is in line with the Dutch study where the frequency of the c.1100delC mutation was significantly elevated compared to that seen in population controls (OR: 4.1, 95\% CI 1.2-14.3, $p=0.05$ ) [10], both studies suggesting about fourto five-fold elevated risk for male breast cancer for the mutation carriers. Very recently, a large American multigene panel study with $715 \mathrm{MBC}$ patients showed that CHEK2 c.1100delC was associated with moderately increased risks of MBC (OR: 3.8, 95\% CI 1.7-7.8) [11].

Mutations in RAD51C and RAD51D are rare and have been primarily linked to an increased risk for ovarian cancer $[19,23]$ rather than breast cancer alone. Previously, no truncating $R A D 51 C$ mutations were identified among 97 Italian $\mathrm{MBC}$ patients and the American multi-gene panel study also did not identify any RAD51C mutations whereas one $R A D 51 D$ mutation was observed among the 715 MBC patients [11, 33]. PALB2 mutations among $\mathrm{MBC}$ patients are relatively rare $(0.8 \%)$ in the US population but have been associated with a significantly increased risk of male breast cancer [11]. In this study, we did not detect the RAD51C, RAD51D, FANCM, or PALB2 mutations among male breast cancer patients. However, our sample size was small. Given the relatively low frequency of RAD51C, RAD51D, FANCM, and PALB2 mutations among unselected female breast cancer patients, the absence of the studied mutations in the MBC series was not unexpected. Larger studies are warranted to better evaluate the contribution of these genes to MBC susceptibility in the Finnish population.

\section{Conclusions}

In conclusion, the CHEK2 c.1100delC mutation is associated with an increased risk for $\mathrm{MBC}$ in the present study in Finnish population. In light of previous data from the Netherlands [10] and USA [11], our study thus suggests that inclusion of CHEK2 mutation analyses should be considered as a part of genetic testing of MBC patients, at least in populations with prevalent mutations.

\section{Additional files}

Additional file 1: Primer pairs used in the genotyping of the CHEK2 c.1100delC and I157T, PALB2 C.1592delT and FANCM C.5101C>T mutations. (DOCX $13 \mathrm{~kb}$ )

Additional file 2: The occurrence of risk factors for male breast cancer. (DOCX $12 \mathrm{~kb})$

\section{Abbreviations}

BMI: Body mass index; Cl: Confidence interval; ER: Estrogen receptor; MBC: Male breast cancer; OR: Odds ratio; PR: Progesterone receptor

\section{Acknowledgements}

We thank research nurses Irja Erkkilä and Outi Utriainen, MSc Salla Ranta, and Silja Suni for their help with collecting the patient samples and data.

\section{Funding}

This study was supported by the Helsinki University Hospital Research Fund, the Academy of Finland (266528), the Sigrid Juselius Foundation, and the Finnish Cancer Society. The funders had no role in study design, collection, analysis, or interpretation of data, or in writing the manuscript.

\section{Availability of data and materials}

The authors declare that the data supporting the findings of this study are available within the article.

\section{Authors' contributions}

SH, LMP, JM and HN designed the study. SH analyzed the patient data and carried out the genotyping. SH and LMP performed the statistical analyzes. SH, LMP, PPS, JM and HN wrote the manuscript. AJ, AJV, PA, CB, and KA contributed samples and patient information. All authors read and approved the final manuscript.

\section{Ethics approval and consent to participate}

The study was approved by The Ethics committee of the Helsinki University Hospital, The Research Ethics Committee of the Northern Savo Hospital District and The Regional Ethics Committee of the Northern Ostrobothnia Hospital District. All individual participants provided written informed consent.

\section{Consent for publication}

Not applicable.

\section{Competing interests}

The authors declare that they have no competing interests.

\section{Publisher's Note}

Springer Nature remains neutral with regard to jurisdictional claims in published maps and institutional affiliations. 


\section{Author details}

Department of Oncology, University of Helsinki and Helsinki University Hospital, Helsinki, Finland. ${ }^{2}$ Department of Obstetrics and Gynecology, University of Helsinki and Helsinki University Hospital, Helsinki, Finland. ${ }^{3}$ Vaasa Central Hospital, Oncologic Clinic, Turku University, Vaasa, Finland. ${ }^{4}$ Department of Oncology and Radiotherapy, Medical Research Center Oulu, Oulu University Hospital and University of Oulu, Oulu, Finland. ${ }^{5}$ Department of Oncology, Kuopio University Hospital and Cancer Center, Institute of Clinical Medicine, University of Eastern Finland, Kuopio, Finland. ${ }^{6}$ Department of Clinical Genetics, University of Helsinki and Helsinki University Hospital, Helsinki, Finland.

Received: 10 February 2017 Accepted: 28 August 2017 Published online: 05 September 2017

\section{References}

1. Deb S, Lakhani SR, Ottini L, Fox SB. The cancer genetics and pathology of male breast cancer. Histopathology. 2016;68:110-8.

2. Brinton LA, Richesson DA, Gierach GL, Lacey JV, Jr., Park Y, Hollenbeck AR, Schatzkin A. Prospective evaluation of risk factors for male breast cancer. J Natl Cancer Inst 2008;100:1477-1481.

3. Syrjäkoski K, Kuukasjärvi T, Waltering K, Haraldsson K, Auvinen A, Borg A Kainu T, Kallioniemi OP, Koivisto PA. BRCA2 mutations in 154 finnish male breast cancer patients. Neoplasia 2004;6:541-545.

4. Lim ET, Wurtz P, Havulinna AS, Palta P, Tukiainen T, Rehnström K, Esko T, Magi R, Inouye M, Lappalainen $T$, et al. Distribution and medical impact of loss-of-function variants in the Finnish founder population. PLoS Genet. 2014;10:e1004494

5. Sarantaus L, Huusko P, Eerola H, Launonen V, Vehmanen P, Rapakko K, Gillanders E, Syrjäkoski K, Kainu T, Vahteristo P, et al. Multiple founder effects and geographical clustering of BRCA1 and BRCA2 families in Finland. Eur J Hum Genet. 2000;8:757-63.

6. Meijers-Heijboer $H$, van den Ouweland A, Klijn J, Wasielewski M, de Snoo A, Oldenburg R, Hollestelle A, Houben M, Crepin E, Van Veghel-Plandsoen M, et al. Low-penetrance susceptibility to breast cancer due to CHEK2 $\left.{ }^{*}\right) 1100$ delC in noncarriers of BRCA1 or BRCA2 mutations. Nat Genet. 2002:31:55-9.

7. Nevanlinna H, Bartek J. The CHEK2 gene and inherited breast cancer susceptibility. Oncogene. 2006;25:5912-9.

8. Vahteristo P, Bartkova J, Eerola H, Syrjäkoski K, Ojala S, Kilpivaara O, Tamminen A, Kononen J, Aittomäki K, Heikkilä P, et al. A CHEK2 genetic variant contributing to a substantial fraction of familial breast cancer. Am J Hum Genet. 2002;71:432-8.

9. Syriäkoski K, Kuukasjärvi T, Auvinen A, Kallioniemi OP. CHEK2 1100delC is not a risk factor for male breast cancer population. Int J Cancer. 2004;108:475-6.

10. Wasielewski M, den Bakker MA, van den Ouweland A, Meijer-van Gelder ME, Portengen H, Klijn JG, Meijers-Heijboer H, Foekens JA, Schutte M. CHEK2 1100delC and male breast cancer in the Netherlands. Breast Cancer Res Treat. 2009;116:397-400.

11. Pritzlaff M, Summerour P, McFarland R, Li S, Reineke P, Dolinsky JS, Goldgar DE, Shimelis H, Couch FJ, Chao EC, et al. Male breast cancer in a multi-gene panel testing cohort: insights and unexpected results. Breast Cancer Res Treat. 2017:161:575-86

12. Kilpivaara $O$, Vahteristo $P$, Falck J, Syrjäkoski K, Eerola H, Easton D, Bartkova J, Lukas J, Heikkilä P, Aittomäki K, et al. CHEK2 variant I157T may be associated with increased breast cancer risk. Int J Cancer. 2004;111:543-7.

13. Pritchard CC, Mateo J, Walsh MF, De Sarkar N, Abida W, Beltran H, Garofalo A, Gulati R, Carreira S, Eeles R, et al. Inherited DNA-repair gene mutations in men with metastatic prostate cancer. N Engl J Med. 2016:375:443-53.

14. Mamrak NE, Shimamura A, Howlett NG. Recent discoveries in the molecular pathogenesis of the inherited bone marrow failure syndrome Fanconi anemia. Blood Rev. 2017;31:93-9.

15. Antoniou A, Pharoah PD, Narod S, Risch HA, Eyfjord JE, Hopper JL, Loman N Olsson $\mathrm{H}$, Johannsson $\mathrm{O}$, Borg $\mathrm{A}$, et al. Average risks of breast and ovarian cancer associated with BRCA1 or BRCA2 mutations detected in case series unselected for family history: a combined analysis of 22 studies. Am J Hum Genet. 2003;72:1117-30.

16. Ramus SJ, Song H, Dicks E, Tyrer JP, Rosenthal AN, Intermaggio MP, Fraser L, Gentry-Maharaj A, Hayward J, Philpott S, et al. Germline Mutations in the BRIP1, BARD1, PALB2, and NBN Genes in Women With Ovarian Cancer. J Natl Cancer Inst. 2015;107:djv214.
17. Antoniou AC, Casadei S, Heikkinen T, Barrowdale D, Pylkäs K, Roberts J, et al. Breast-cancer risk in families with mutations in PALB2. N Engl J Med. 2014;371:497-506

18. Pelttari LM, Heikkinen T, Thompson D, Kallioniemi A, Schleutker J, Holli K, Blomqvist C, Aittomäki K, Bützow R, Nevanlinna H. RAD51C is a susceptibility gene for ovarian cancer. Hum Mol Genet 2011;20:3278-3288.

19. Loveday C, Turnbull C, Ruark E, Xicola RM, Ramsay E, Hughes D, WarrenPerry M, Snape K, Eccles D, Evans DG, et al. Germline RAD51C mutations confer susceptibility to ovarian cancer. Nat Genet. 2012;44:475-6.

20. Sawyer SL, Tian L, Kahkonen M, Schwartzentruber J, Kircher M, Majewski J, Dyment DA, Innes AM, Boycott KM, Moreau LA, et al. Biallelic mutations in BRCA1 cause a new Fanconi anemia subtype. Cancer Discov. 2015;5:135-42.

21. Erkko H, Xia B, Nikkilä J, Schleutker J, Syrjäkoski K, Mannermaa A, Kallioniemi A, Pylkäs K, Karppinen SM, Rapakko K, et al. A recurrent mutation in PALB2 in Finnish cancer families. Nature. 2007:446:316-9.

22. Heikkinen T, Kärkkäinen H, Aaltonen K, Milne RL, Heikkilä P, Aittomäki K, Blomqvist C, Nevanlinna $\mathrm{H}$. The breast cancer susceptibility mutation PALB2 1592delT is associated with an aggressive tumor phenotype. Clin Cancer Res. 2009;15:3214-22.

23. Loveday C, Turnbull C, Ramsay E, Hughes D, Ruark E, Frankum JR, Bowden G, Kalmyrzaev B, Warren-Perry M, Snape K, et al. Germline mutations in RAD51D confer susceptibility to ovarian cancer. Nat Genet. 2011:43:879-82.

24. Pelttari LM, Kiiski J, Nurminen R, Kallioniemi A, Schleutker J, Gylfe A, Aaltonen LA, Leminen A, Heikkilä P, Blomqvist C, et al. A Finnish founder mutation in RAD51D: analysis in breast, ovarian, prostate, and colorectal cancer. J Med Genet. 2012:49:429-32.

25. Kiiski Jl, Pelttari LM, Khan S, Freysteinsdottir ES, Reynisdottir I, Hart SN, Shimelis H, Vilske S, Kallioniemi A, Schleutker J, et al. Exome sequencing identifies FANCM as a susceptibility gene for triple-negative breast cancer. Proc Natl Acad Sci U S A. 2014;111:15172-7.

26. Fagerholm R, Hofstetter B, Tommiska J, Aaltonen K, Vrtel R, Syrjäkoski K, Kallioniemi A, Kilpivaara O, Mannermaa A, Kosma VM, et al. NAD $(P) H$ : quinone oxidoreductase $1 \mathrm{NQO}^{*} 2$ genotype (P187S) is a strong prognostic and predictive factor in breast cancer. Nat Genet. 2008;40:844-3.

27. de Bock GH, Schutte M, Krol-Warmerdam EM, Seynaeve C, Blom Brekelmans CT, Meijers-Heijboer H, van Asperen CJ, Cornelisse CJ, Devilee P, et al. Tumour characteristics and prognosis of breast cancer patients carrying the germline CHEK2*1100delC variant. J Med Genet. 2004;41:731-5.

28. Hale V, Weischer M, Park JY. CHEK2 (*) 1100delC Mutation and Risk of Prostate Cancer. Prostate Cancer 2014;2014:294575.

29. Choi DH, Cho DY, Lee MH, Park HS, Ahn SH, Son BH, Haffty BG. The CHEK2 1100 delC mutation is not present in Korean patients with breast cancer cases tested for BRCA1 and BRCA2 mutation. Breast Cancer Res Treat 2008:112:569-73.

30. Offit K, Pierce H, Kirchhoff T, Kolachana P, Rapaport B, Gregersen P, Johnson $\mathrm{S}$, Yossepowitch O, Huang H, Satagopan J, et al. Frequency of CHEK2*1100delC in New York breast cancer cases and controls. BMC Med Genet. 2003:4:1

31. Ohayon T, Gal I, Baruch RG, Szabo C, Friedman E. CHEK2*1100delC and male breast cancer risk in Israel. Int J Cancer 2004;108:479-480.

32. Neuhausen S, Dunning A, Steele L, Yakumo K, Hoffman M, Szabo C. Tee L, Baines C, Pharoah P, Goldgar D, et al. Role of CHEK2*1100delC in unselected series of non-BRCA1/2 male breast cancers. Int J Cancer. 2004;108:477-8.

33. Silvestri V, Rizzolo P, Falchetti M, Zanna L, Masala G, Palli D, Ottini L. Mutation screening of RAD51C in male breast cancer patients. Breast Cancer Res. 2011:13:404 